\title{
Capacitance measurements on integrated conductors for detection of matrix cracks in GFRP
}

\author{
Christina Buggisch ${ }^{1 *}$ (D), Abedin Gagani ${ }^{1,2}$ and Bodo Fiedler ${ }^{1}$
}

\begin{abstract}
For the reliable and cost-efficient application of glass fibre polymer composites in structural applications, knowledge of the damage state of the material during operation is necessary. Within this work, a structural health monitoring method based on in-situ electrical capacitance measurements is presented, which enables damage monitoring in glass fibre reinforced polymers. For this purpose, individual glass fibre rovings in a non-crimp fabric were replaced by carbon fibre rovings at regular intervals. Additionally, specimens with solid or stranded copper conductors were manufactured to gain insights into the influences of conductor material and composition. The modified fabrics were implemented as $90^{\circ}$ layers of $\left[0 / 90_{4}\right]_{s}$ glass fibre polymer cross-ply laminates. To monitor the progressive damage, conductive rovings were contacted, forming the capacitor walls of interleaved capacitors. Carbon fibre conductors show higher sensitivity of the capacitance to crack formation than solid or stranded copper conductors. Capacitance decrease measured in-situ during tensile tests on specimens with carbon fibre conductors shows a high correlation with crack initiation, further crack formation and speed of crack evolution. An analytical model can describe the correlation based on the assumptions of an ideal plate capacitor. Thus, the structural health monitoring method developed in this work can reveal in-situ knowledge of the material damage state.
\end{abstract}

Keywords: Structural health monitoring, Carbon fibre electrode, Tensile tests, Electrical measurements

\section{Introduction}

Glass fibre reinforced polymers (GFRP) are used in numerous structural applications, where the reliability of the structures is essential for operation. To ensure the safety of operation, an inspection of structural parts is performed at regular intervals using non-destructive testing (NDT) methods like ultrasonic inspection or thermography. Most NDT inspections can only be carried out locally and during maintenance, which can lead to late detection of damage, frequent maintenance intervals and expensive downtimes. Especially in large complex components, some parts of the structure can only be tested with difficulty or not at all using NDT methods. To increase

\footnotetext{
*Correspondence: christina.buggisch@tuhh.de

'Hamburg University of Technology, Institute of Polymer and Composites, Denickestraße 15, 21073 Hamburg, Germany

Full list of author information is available at the end of the article
}

reliability and cost-efficiency and to exploit higher potentials of lightweight design, various structural health monitoring (SHM) techniques have been developed to monitor the material integrity during service. Especially in carbon fibre reinforced polymers, electrical resistance measurements for strain and damage detection are an established SHM technique which enables monitoring of the whole structure [1-5]. However, resistive monitoring is not possible in unmodified GFRP parts like wind turbine rotor blades due to the lack of material conductivity. Resistive SHM of polymers or GFRP can be achieved with modification of the matrix using conductive nanoparticles $[3,6-8]$. Particularly for large structures, a modification of the entire matrix is expensive. Local reinforcements with conductive fillers are part of ongoing research [9-14].

In contrast to resistance measurements, capacitance measurements using integrated or surface electrodes can 
be performed on non-conductive materials. The detection capability of capacitance-based methods relies on a change of dielectric properties of the material. In concrete structures capacitance measurements are applied for the detection of cracks or voids $[15,16]$, rebar reinforcement corrosion and localisation $[17,18]$ as well as detection of moisture [19, 20]. Coplanar electrode pairs without surface contact are used during capacitive imaging to scan across a surface measuring changes in charge for given voltages resulting in a map of electrical property changes enabling detection of cracks, voids or moisture [21]. However, for polymers or fibre-reinforced polymers, research on capacitance measurements for damage detection is limited. Chakraborty et al. [22,23] used capacitance measurements for stress and interlayer defect detection in 3D-printed polymers. In CFRP, Kupke et al. [3] measured a capacitance decrease on cross-ply specimens during insitu measurements in tensile tests. Abry et al. [24] also performed in-situ measurements on CFRP specimens and found a capacitance decrease related to matrix cracks and intra-ply delaminations during flexural loading. However, direct quantitative correlation between cracks and capacitance change in CFRP still remains a challenge for many methods. As in concrete, capacitative imaging with coplanar non-contact electrodes can also be used for moisture or damage detection and localisation in different FRP composites as CFRP, honeycomb structures and GFRP $[25,26]$. Recently, piezoelectric sensors embedded in FRP have also been used as capacitance sensors $[27,28]$ instead of just as acoustic emission $[29,30]$ or voltage sensors [31-34] as established by many research groups (review in [35]). It was shown that capacitance measurements on embedded piezoelectric transducers are in good agreement with loading and unloading trends in different tensile tests on GFRP [28]. The first report of capacitance-based self-sensing without embedded or attached sensors on CFRP was given by Eddib [36] using an LCR meter and an insulating film between the CFRP and the measuring electrode. Through thickness and in-plane capacitance measurements were capable of detecting artificial damage introduced by $1.1 \mathrm{~mm}$ big through-holes in CFRP. In GFRP detection of drilled holes and moisture influence using a capacitance bridge was shown by Asmatulu [37]. In-situ moisture detection in composites is possible with impedance spectroscopy [38], where the impedance of the material is measured for different frequencies. Methods enabling insitu damage detection and material damage state estimation during operation are still limited and part of ongoing research. Within this study, an in-situ SHM technique for damage detection and state estimation in GFRP based on capacitance change due to dielectric changes introduced by evolving matrix cracks is established. Therefore, individual rovings of a glass-fibre fabric have been replaced by conductive carbon fibre (CF) rovings, solid and stranded copper wires forming the capacitor walls of an interleaved capacitor enabling monitoring of capacitance change during tensile tests.

\section{Materials and methods}

\section{Materials and specimen preparation}

Individual rovings of Gurit UT-E250 non-crimp UD glassfibre fabric were replaced at regular intervals with $\mathrm{CF}$ rovings FT300B 6000-50B (Torayca), copper wires with an approximate diameter of $1.5 \mathrm{~mm}$ and copper strands. The three conductor types were used to gain insights in influences of conductor material and effects of fibrous conductor composition on the mechanical and electrical properties. The choice of conductors was made according to the geometric specifications of the glass fibre roving and the fabric as well as laminate thickness. Figure 1 shows the steps performed during roving replacement with CF roving exemplary for all roving types. First, the stitching yarns were detached from the glass fibre roving, and the roving was removed. Afterwards, the CF roving was threaded into the fabric in the same manner as the glass fibre rovings. For the copper strands, the replacement process was similar. In case of the solid copper wire, the wire was inserted in the middle $90^{\circ}$ fabric, and in all other $90^{\circ}$ fabrics only the glass fibre rovings were removed. Specimens with conductor spacings of $13 \mathrm{~mm}$ and $18 \mathrm{~mm}$ were manufactured to understand the influence of the conductor spacing. Modified fabrics were used in all $90^{\circ}$ plies of a $\left[0 / 90_{4}\right]_{s}$ composite. When stacking the plies, special care was taken to ensure a consistent alignment of the conductive rovings of all $90^{\circ}$ plies. The $0^{\circ}$ layers consisted of unmodified glass-fibre fabrics of the same type.

The $2 \mathrm{~mm}$ thick laminates were manufactured in vacuum-assisted resin transfer moulding (RTM) process using the two-component epoxy system Hexion EPIKOTE $^{\text {"m }}$ Resin MGS ${ }^{\text {m" }}$ RIMR 135 and EPIKURE Curing Agent MGS ${ }^{\text {m" }}$ RIMH 137 with a mixing ratio of 100:30 weight shares. Curing was performed at $50^{\circ} \mathrm{C}$ for $16 \mathrm{~h}$. Post-curing was carried out for $16 \mathrm{~h}$ at $80^{\circ} \mathrm{C}$ in an oven. Tensile specimens were cut according to the dimensional specifications given in DIN EN ISO 527-4 [39] using an ATM Brillant 265 saw. Additionally, GFRP specimens of different lengths were cut for permittivity measurements.

These specimens were contacted at the face sides using Acheson 1415 conductive silver paint. The conductors inside the tensile specimens were contacted to form interleaved capacitors, as shown in Fig. 2. Electrical contacting was done using Acheson 1415 conductive silver paint and LiFy cables with a cross-section of $0.25 \mathrm{~mm}$. Few CF roving conductors were short-circuited due to single fibres touching the adjacent roving after the infusion process. These parts of the specimen were not included when 


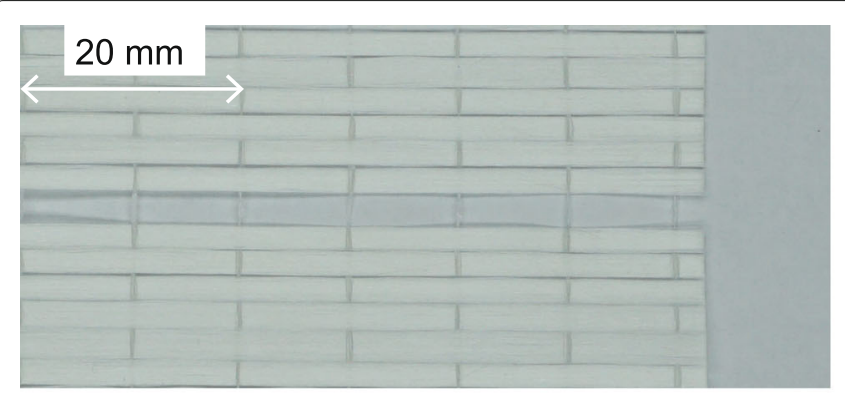

a)

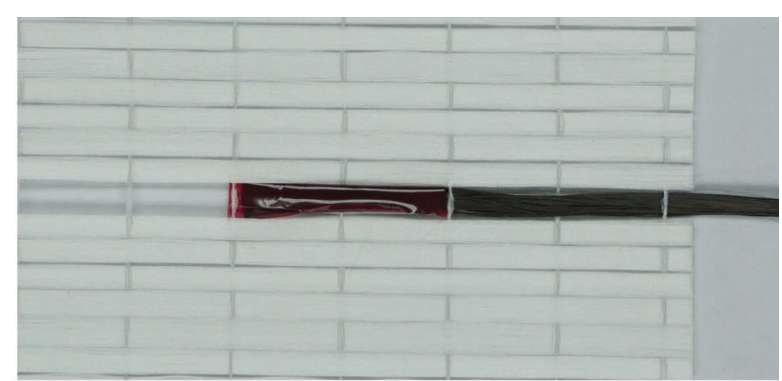

b)

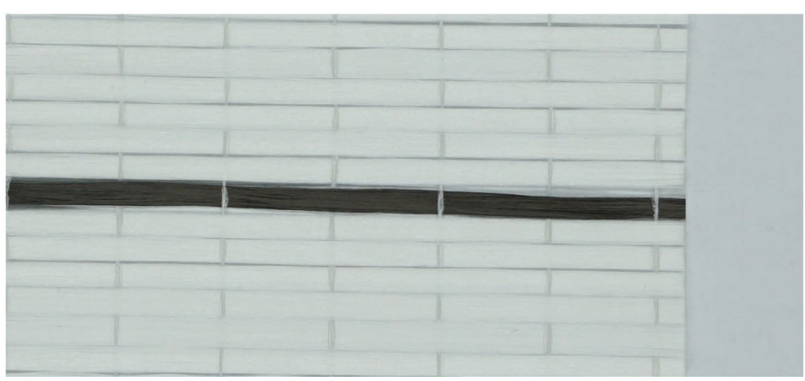

c)

Fig. 1 Replacement of glass fibre rovings. a glass fibre fabric with removed glass fibre roving, b Exemplary replacement of glass fibre roving with carbon fibre roving, c glass fibre fabric with inserted carbon fibre roving

contacting the interleaved capacitor leading to different amounts of capacitor walls.

\section{Test setup}

Tensile tests were performed on a $400 \mathrm{kN}$ universal testing machine (ZwickRoell GmbH \& Co. KG, Ulm, Germany). The strain was measured using a multiXtens extensometer. The test speed was $1 \mathrm{~mm} \mathrm{~min}^{-1}$ as specified in DIN EN ISO 527-4 [39]. The free gauge length and distance between the extensometers were modified from the norm values so that all conductors of the interleaved capacitor were in the free gauge length (18 mm spacing: $195 \mathrm{~mm}$ gauge length, $13 \mathrm{~mm}$ spacing: $155 \mathrm{~mm}$ gauge length). Quasi-static tensile tests up to failure and force-controlled step-wise tensile tests were performed. For all configurations and tests between three and 10 specimens were tested. During the step-wise tests five force levels $2600 \mathrm{~N}$, $3000 \mathrm{~N}, 3400 \mathrm{~N}, 4000 \mathrm{~N}$ and $6800 \mathrm{~N}$ were applied which approximately correspond to strains of $0.3 \%, 0.4 \%, 0.5 \%$, $0.7 \%$ and $1.5 \%$. During all tensile tests, the capacitance

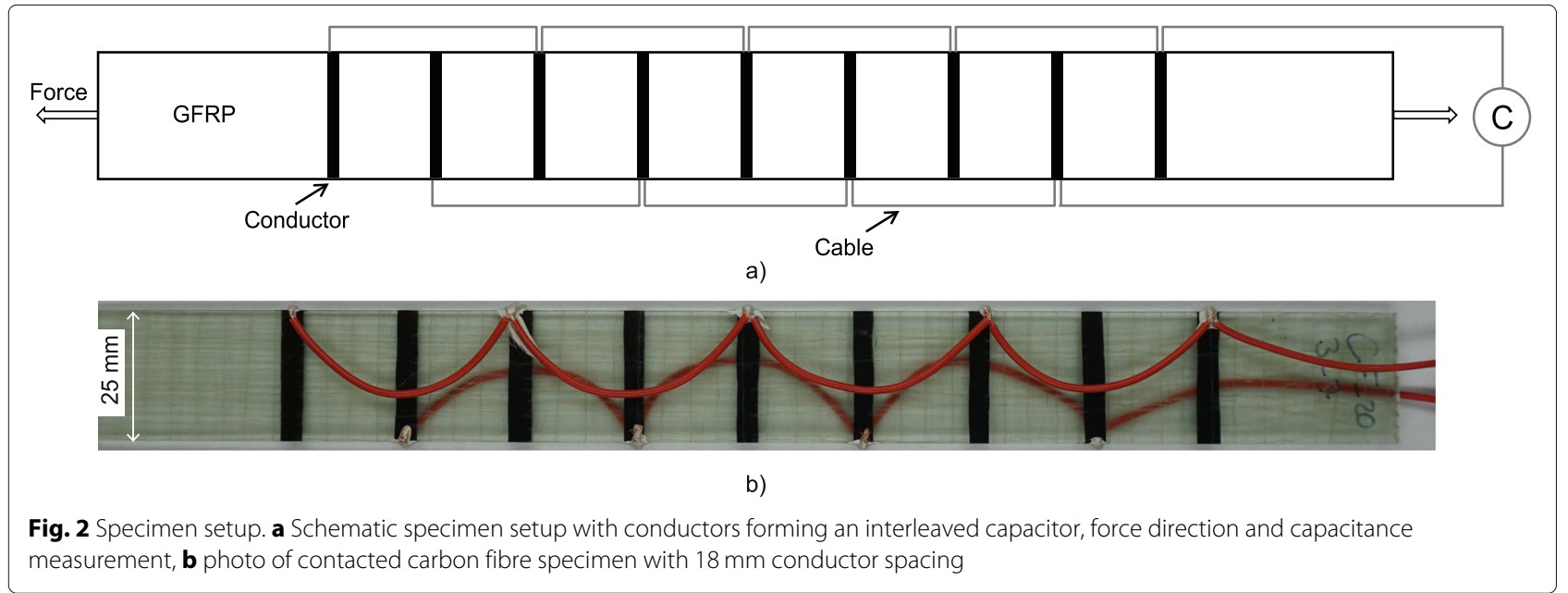


was measured in-situ with a four-wire sensing setup using a Peaktech 2170 LCR meter. The measuring frequency was $10 \mathrm{kHz}$, and the sampling frequency was $2 \mathrm{~Hz}$. In a sensitivity study between $100 \mathrm{~Hz}$ and $100 \mathrm{kHz}$, the measuring frequency of $10 \mathrm{kHz}$ achieved the best compromise between high sensitivity and low scattering of the measurement signal compared to all measuring frequencies possible with the Peaktech 2170 LCR meter. To minimise the influence of external factors on the capacitance measurements, the cables of the measuring device were secured against movement, and the tensile machine was grounded electrically. Additionally, a video of the specimens was taken for crack evolution monitoring using a camera of an Aramis digital image correlation (DIC) system. The force was synchronised between DIC and test machine via an analogue output. An LED providing backlight was used to make the cracks more visible in the video.

\section{Results and discussion}

Permittivity determination and capacitance measurements To determine the permittivity of the material $\epsilon_{r}$ in tensile direction, capacitance measurements were carried out on samples of different lengths. The inverted values of the measured capacitance $C_{m}$ were plotted over the respective sample lengths, as shown in Fig. 3. The permittivity is calculated following Eq. 1 [22] from the slope of the linear regression fit, which depicts the measured values well.

$$
\text { slope }=\frac{1}{\epsilon_{0} \epsilon_{r} A}
$$

The calculated relative permittivity of the material $\epsilon_{r}$ is 46 . This value is relatively high compared to different values of GFRP in literature [40, 41]. Various reasons might be the cause. Thinking of the specimen as ideal plate capacitor the plate area formed by conductive silver paint on two edges of the specimen is small in comparison to the thickness of the capacitor given by the length of the specimen. Therefore, a strongly curved and reoriented electric field is present in the air around the edges of the specimen. This fringing electric field leads to a higher apparent capacitance, which results in a higher apparent permittivity. This effect was also found in concrete by Wang et al. [42]. The effect of fringing electric fields on the permittivity becomes higher, the higher the thickness of the capacitor (see schmatic in Fig. 4). To support this theory, the permittivity of the material was also determined in the thickness direction of the material on specimens with $400 \mathrm{~mm}^{2}$ area providing a significantly larger area and smaller distance. In this case, the permittivity calculated from capacitance measurements was only around 6. Additionally, the permittivity shows frequency-dependent behaviour increasing with lower frequency, and within this study, a low frequency of $10 \mathrm{kHz}$ is used compared with the $\mathrm{MHz}$ or $\mathrm{GHz}$ used in literature $[40,41]$. However, the permittivity value itself is not essential for further experiments since only the relative capacitance change is considered during tensile tests.

In an idealised view, the conductors (CF, solid copper and copper strands) inside the tensile specimens can be regarded as plates of a plate capacitor. Equation 2 describes the capacitance of an ideal plate capacitor using

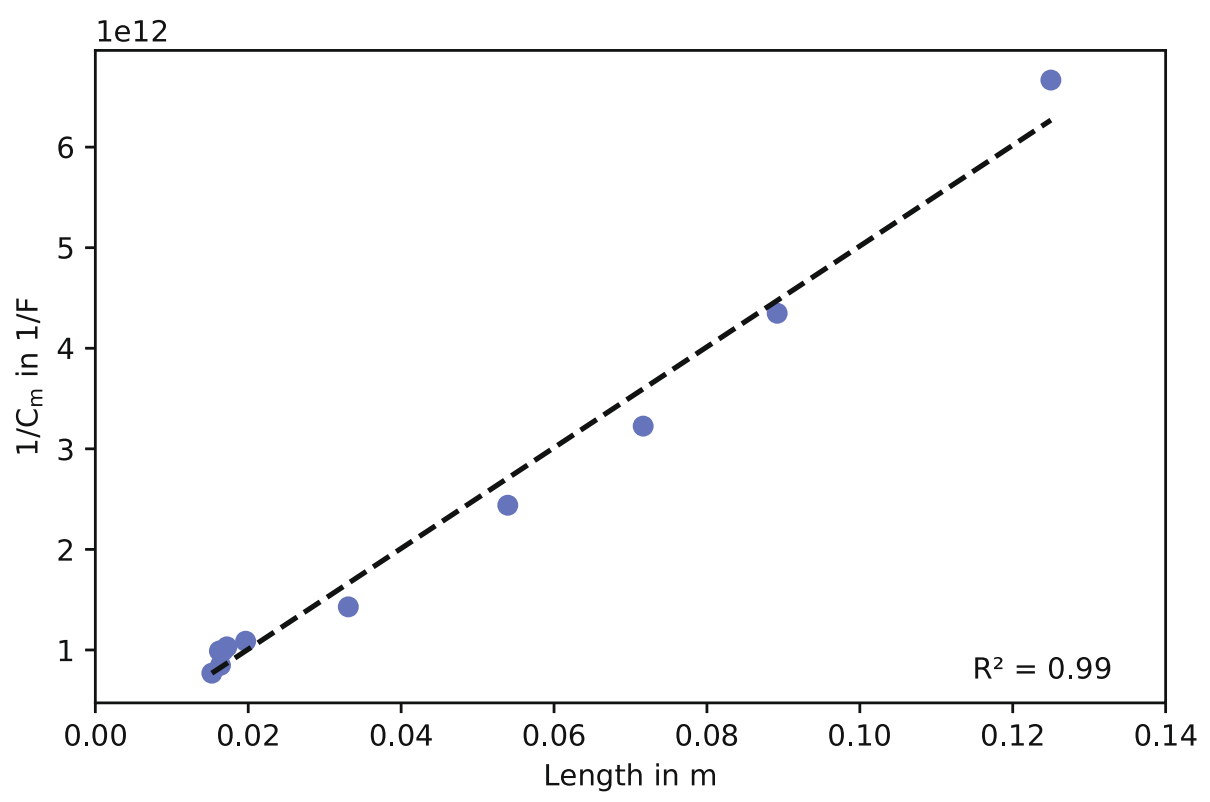

Fig. 3 Measurement values for $1 / C_{m}$ over the length. Plot for the determination of permittivity of the GFRP 


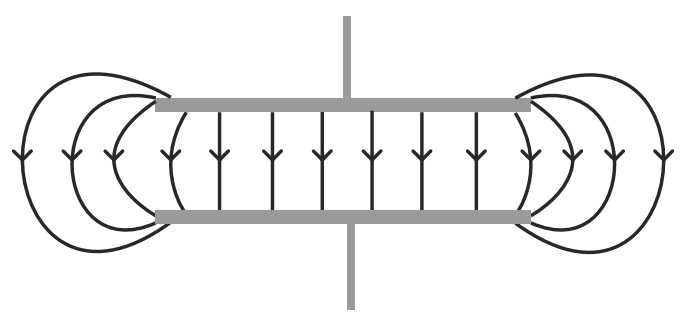

a)

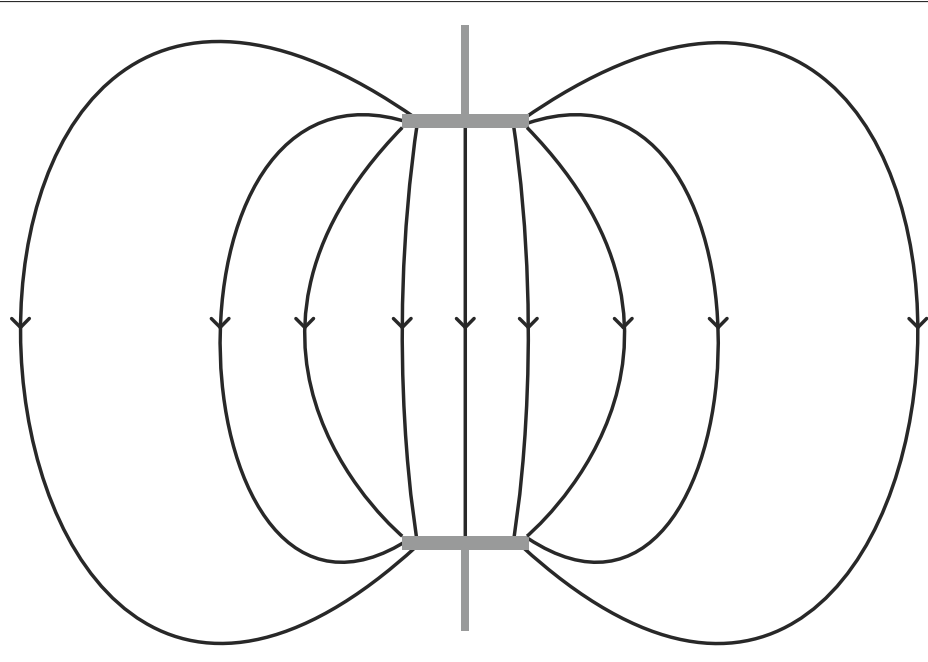

b)

Fig. 4 Fringing electric field around a plate capacitor. 2D schematic visualisation of the electric field of a plate capacitor for $\mathbf{a}$ small thickness and $\mathbf{b}$ high thickness

the permittivity of vacuum $\epsilon_{0}$, the permittivity of the dielectric medium $\epsilon_{r}$ and the area $A$ and distance $d$ of the plates.

$$
C=\epsilon_{0} \epsilon_{r} \frac{A}{d}
$$

The distance $d$ between the conductors is approximately $13 \mathrm{~mm}$ for the narrow and $18 \mathrm{~mm}$ for the wider conductor spacing. The area $A$ is calculated as the thickness of the $90^{\circ}$ layer $d_{90}$ times the specimen width $w$. Using the measured permittivity value of GFRP, the capacitance of a single plate capacitor is calculated to $1.17 \mathrm{pF}$ for the smaller distance. This theoretical value is in good agreement with the measurement values $1.21 \pm 0.33 \mathrm{pF}$ of the specimens with $\mathrm{CF}$ conductors. Micro-sections of the conductors shown in Fig. 5 reveal the limitations of the assumption of ideal plates with uniform distance and rectangular area calculated from $90^{\circ}$ layer thickness and specimen width. Due to

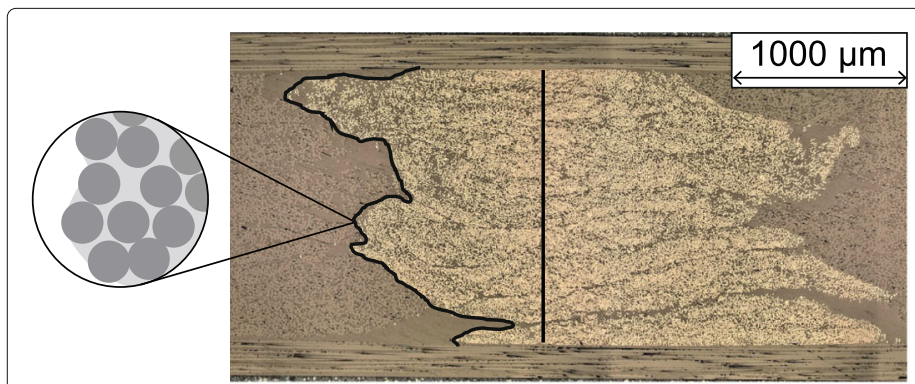

a)

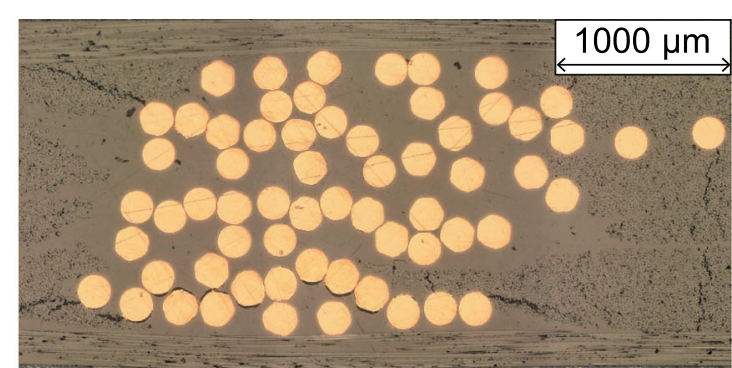

b)

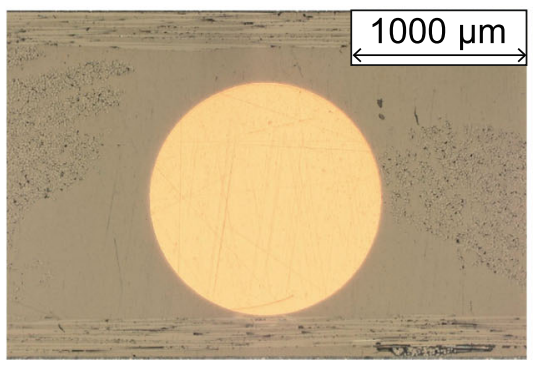

c)

Fig. 5 Micro-sections of conductors in tested specimens. Side-view on conductors $\mathbf{a}$ CF, b stranded copper wire, c solid copper wire 
imperfect alignment of the conductive rovings in the single plies and movement of the layers during infusion, the distance between the conductors is non-uniform over the thickness of the $90^{\circ}$ layer in case of CF and stranded copper conductors. This effect results in a significantly larger area of the conductors since the thickness of the $90^{\circ}$ layer is smaller than the actual length of the conductor surface in thickness direction. On micro-scale, as shown in the schematic enlargement the surface area of the fibrous conductors is not flat due to the geometry of the fibrous resulting in a bigger conductor surface. In case of solid copper conductors, the effects are qualitatively similar due to the circular cross-section of the conductor.

\section{Quasi-static tensile tests}

Comparing the mean tensile strength values of the specimens with the three conductor configurations and both spacings with non-modified reference specimens, a slight decrease of maximum $6 \%$ in case of the solid copper conductors is visible (see Fig. 6). However, the decrease is not pronounced as all standard deviations overlap. The outer $0^{\circ}$ layers mainly determine the tensile strength. Hence, the replacement of single bundles in the $90^{\circ}$ layer of the cross-ply specimens does not significantly change the tensile strength of the material. The Young's modulus of the specimens is shown in Fig. 7. The integration of the CF conductors does not change the Young's modulus significantly. There is a slight decreases of $1.21 \%$ for $13 \mathrm{~mm}$ spacing and $0.79 \%$ for $18 \mathrm{~mm}$ spacing. In case of the stranded and solid copper conductors, the Young's modulus is lowered between $9.21 \%$ and $14.44 \%$. The micro-sections of the conductors in Fig. 5 show that resin-rich regions are present around the copper conductors. These resin-rich regions result in a lower fibre volume fraction and hence a lower Young's modulus.

Figure 8 shows representative results of tensile tests on specimens with all conductor types. The development of matrix cracks in the specimens starts between $0.3 \%$ and $0.4 \%$ strain. After crack initiation, there is a rapid formation of new cracks. With increasing strain, fewer cracks develop. The crack initiation and rapid crack development are visible in the stress-strain curve as a stiffness decrease (knee point). Figure 9 shows the crack development in two segments of a CF conductor specimen with $18 \mathrm{~mm}$ conductor spacing for $0.5 \%$ strain, $0.7 \%$ strain, and $1.5 \%$ strain. In the pictures with $0.5 \%$ and $0.7 \%$ strain the individual cracks are easily recognizable as solid black lines and mostly spanning the whole specimen width. For higher strains, the crack pattern is more diffuse. Cracks are no longer visible as clear black lines but as grey shadows, which are sometimes difficult to distinguish from the yarn. It is also noticeable that many cracks no longer span the entire specimen width. These effects lead to a possible underestimation of counted cracks.

The in-situ capacitance measurements show different behaviour for the three conductor types (see Fig. 8). Therefore, the y-axes' scales of the capacitance change vary for the single subplots. The capacitance change $\Delta C$ in per cent is calculated according to formula 3 using the current capacitance $C$ and the initial capacitance $C_{0}$. The percentage-wise capacitance change is independent of the

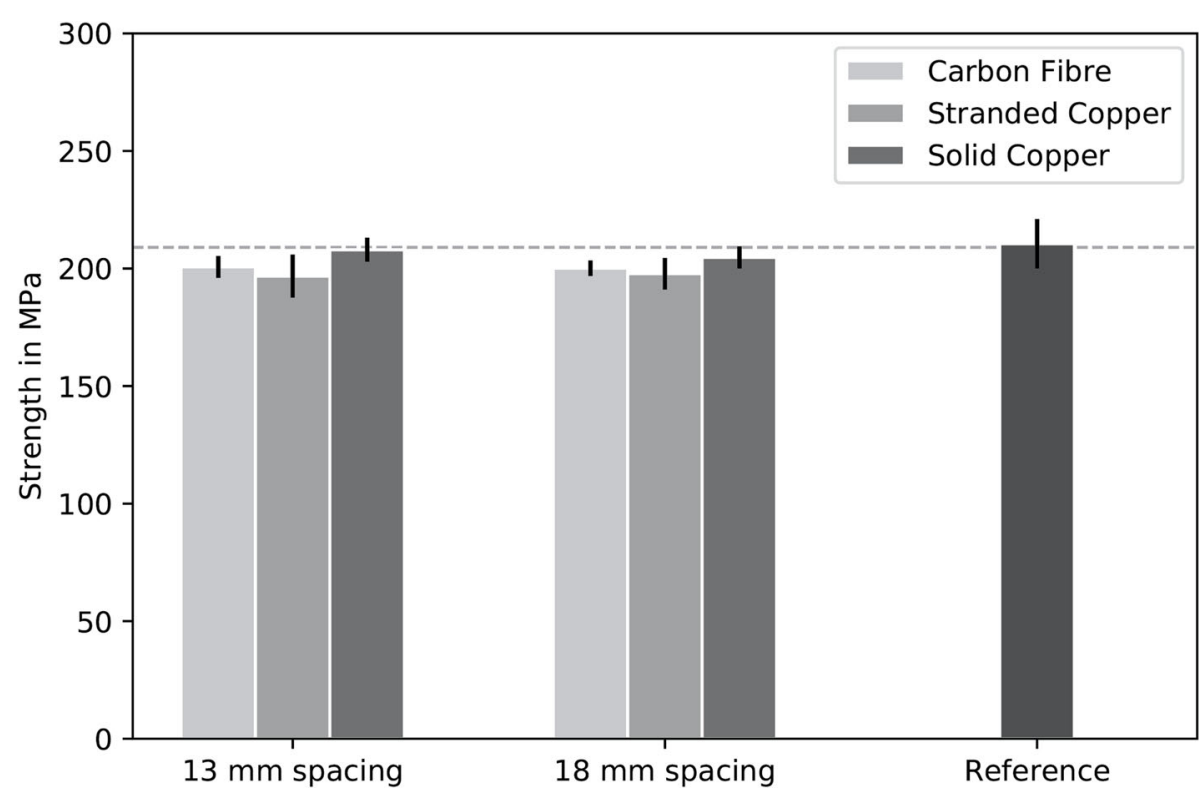

Fig. 6 Strength of the $\left[0 / 90_{4}\right]_{s}$ cross-ply GFRP specimens in MPa for different conductor configurations (carbon fibre, stranded copper, solid copper) and distances $(13 \mathrm{~mm}$ and $18 \mathrm{~mm}$ ) compared with reference specimens without conductors 


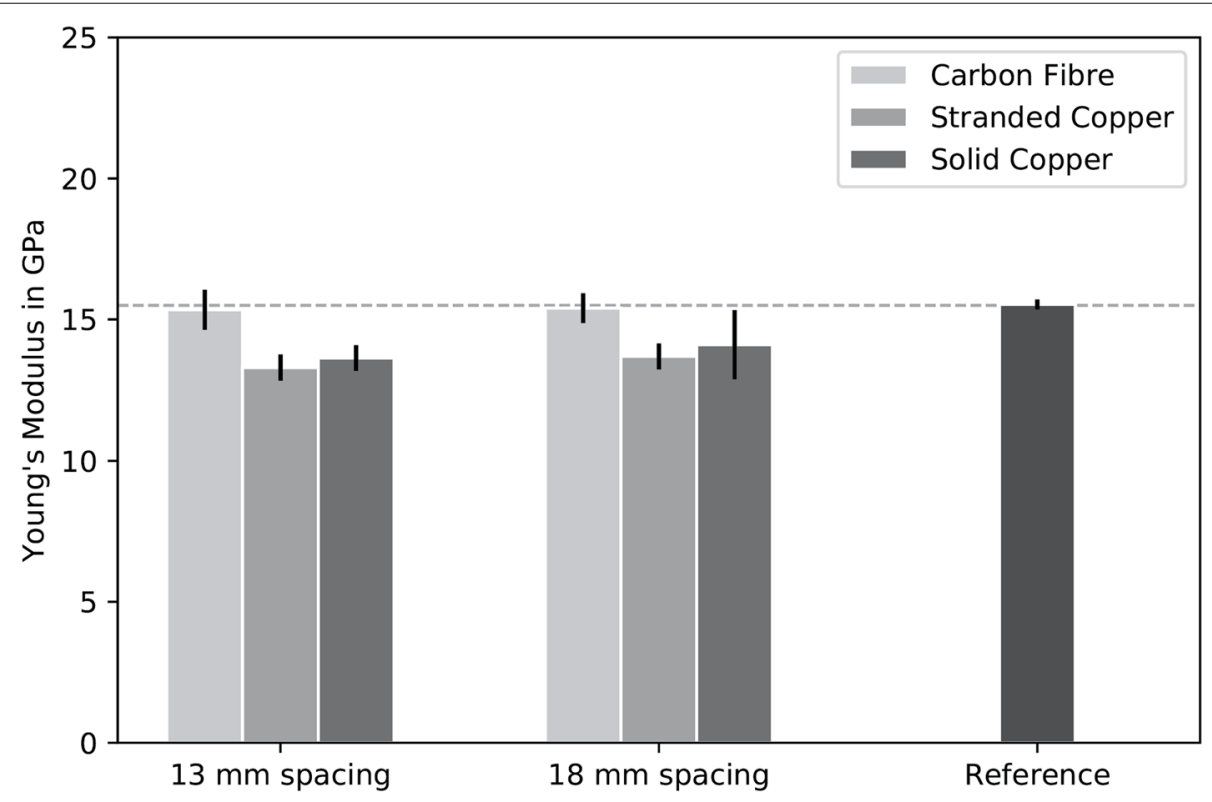

Fig. 7 Young's modulus of the $\left[0 / 90_{4}\right]_{s}$ cross-ply GFRP specimens in GPa for different conductor configurations (carbon fibre, stranded copper, solid copper) and distances $(13 \mathrm{~mm}$ and $18 \mathrm{~mm}$ ) compared with reference specimens without conductors

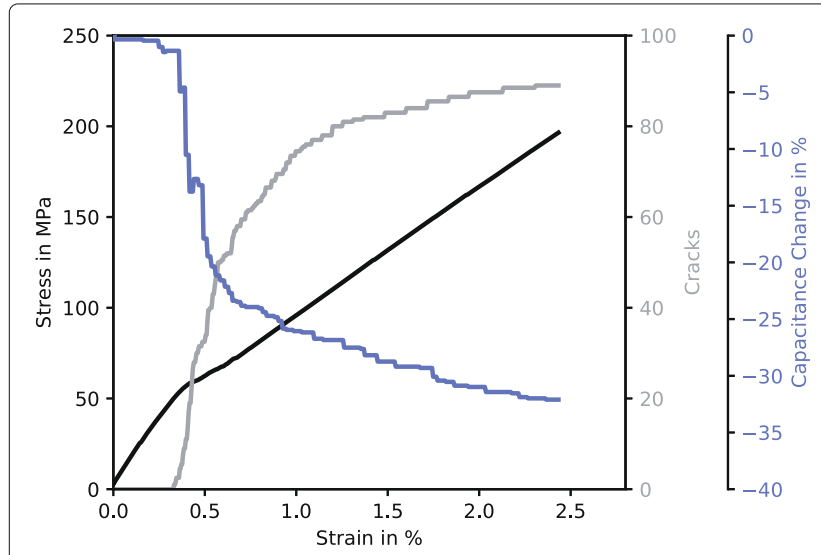

a)

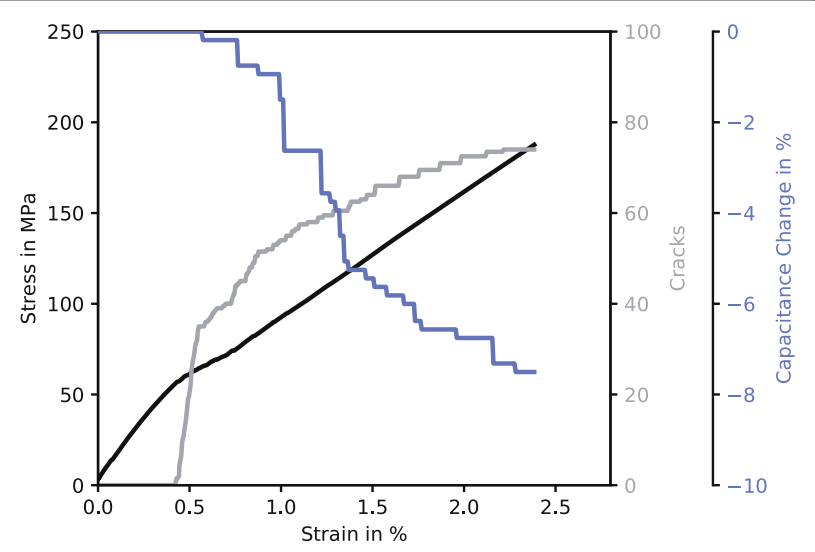

b)

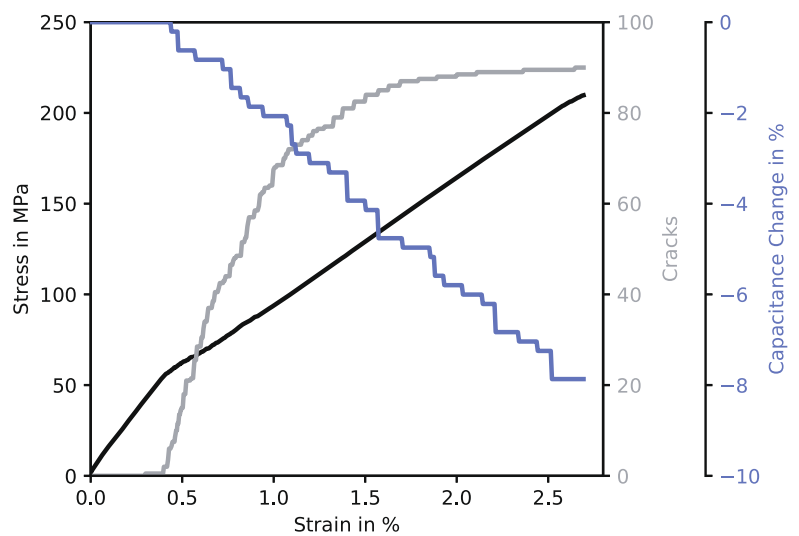

c)

Fig. 8 Results of representative tensile tests. Plots showing stress in MPa, capacitance change in \% and counted cracks over strain for tensile tests on representative specimens with a carbon fibre conductors, b stranded copper conductors, $\mathbf{c}$ solid copper conductors 


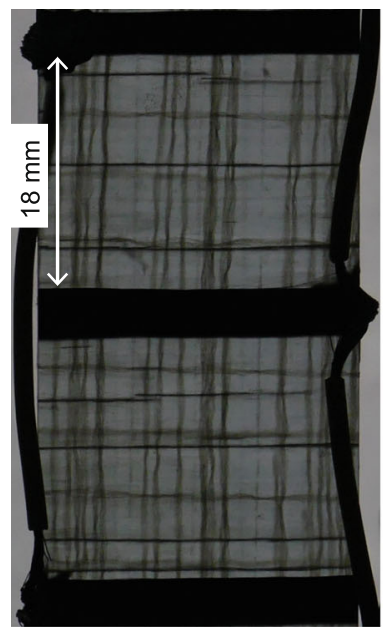

a)

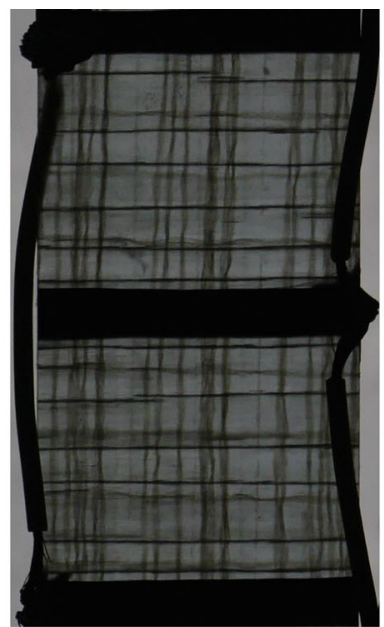

b)

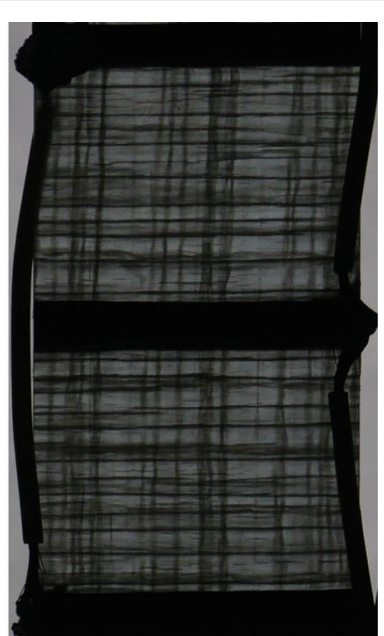

c)

Fig. 9 Crack evolution in representative specimen with carbon fibre conductors at a $0.5 \%$ strain, b $0.7 \%$ strain, c $1.5 \%$ strain

number of contacted rovings forming the capacitor walls of the interleaved capacitor.

$$
\Delta C=\frac{C-C_{0}}{C_{0}} 100
$$

In the specimens with CF conductors, the measured capacitance starts to decrease strongly during rapid crack growth and the decrease is slowing down with the formation of fewer new cracks reaching a maximum value of $32 \%$. There is a strong correlation between the counted transverse cracks and the capacitance change. Therefore, the development of cracks is assumed to be the major effect influencing the capacitance change. Furthermore, no debonding of $\mathrm{CF}$ and the surrounding resin is visible in the micro-sections of tested specimens (see Fig. 5).

The capacitance decrease in tensile tests with specimens with stranded copper conductors is overall a little delayed compared to the crack evolution (see Fig. 8). The capacitance does not decrease directly after crack initiation but stays constant for some additional strain. The gradient of the capacitance decrease continues to decrease as the tensile test progresses. However, the capacitance does not decrease as much with crack formation than visible for the CF conductors. The maximum capacitance decrease is around $8 \%$ and thus approximately factor 4 smaller than in specimens with CF conductors. In the micro-sections a debonding of some copper strands from the surrounding matrix is visible.

For solid copper conductors, the point of capacitance change crack initiation can precisely be detected as a slope change in the capacitance decrease. Before crack initiation, no capacitance change is visible. After crack initiation, a linear decrease of the capacitance change is visible. However, the slope of the capacitance change is not changing until the end of the test. Faster or slower crack evolution has no measurable effect on the capacitance decrease. The maximum capacitance change is similar to the stranded copper conductors around $7.5 \%$. The solid copper conductors do not debond from the surrounding matrix.

The CF conductors show the highest sensitivity to capacitance changes due to cracks comparing the quantitative amount and qualitative shape of the measured capacitance change. Micro-sections of the conductors (see Fig. 5) show that in the case of CF conductors no resin-rich area is present between the conductor and the surrounding GFRP. For stranded copper conductors the resin-rich area between the single strands and around the conductors is bigger. An even bigger resin-rich area is present around the solid copper conductors. The CF conductors are formed of $86 \mathrm{~K}$ rovings consisting of $\mathrm{CF}$ with a nominal diameter of $7 \mu \mathrm{m}$. Stranded copper conductors consist of 64 copper strands with a diameter of $186 \mu \mathrm{m}$. The single solid copper wire has a diameter of $1319 \mu \mathrm{m}$. The total surface area of the CF in contact with the matrix is factor 28.2 higher than for the stranded copper wires and factor 255 higher than for the solid copper. The fibrous nature of the conductors leads to a higher sensitivity of capacitance change to crack formation. The CF and stranded copper wires both show a regressive drop in capacitance with a progressive increase in cracks, whereas for the solid copper wires only a linear drop can be measured. Another reason for the sensitivity difference could be the material difference between carbon and copper. CF conductors show a four-times bigger total capacitance change than both copper conductor configurations. 


\section{Analytical modelling}

Analytical modelling of the capacitance decrease is possible when considering the conductors as plates of an ideal plate capacitor with a uniform electric field. As for the permittivity determination, the distance between the conductors is assumed to be uniform over the thickness of the $90^{\circ}$ layer and the area of the conductors is calculated as rectangular area $A$ determined from the thickness of the $90^{\circ}$ layer $d_{90}$ and the specimen width $w$. Initially, there is only GFRP as a dielectric medium between the plates. The elongation of the specimen results in a distance change of the conductors. The pure distance change leads to a linear capacitance decrease proportional to the introduced strain. However, the appearance of cracks introduces air as a second dielectric medium between the conductors. Thus after crack initiation, Eq. 2 changes to Eq. 4, which takes into account the different permittivities of GFRP $\epsilon_{\mathrm{r}, \mathrm{GFRP}}$ and air $\epsilon_{\mathrm{r}, \text { air }}$. Figure 10 shows a schematic of the idealised capacitor in the specimen with the assumption of uniform rectangular cracks and a plate capacitor with two dielectrics.

$$
C=\epsilon_{0} A \frac{\epsilon_{\mathrm{r}, \mathrm{GFRP}} \epsilon_{\mathrm{r}, \mathrm{air}}}{d_{\mathrm{GFRP}} \epsilon_{\mathrm{r}, \mathrm{air}}+d_{\mathrm{air}} \epsilon_{\mathrm{r}, \mathrm{GFRP}}}
$$

The previously determined apparent permittivity $\epsilon_{\mathrm{r}, \mathrm{GFRP}}$ of 46 is used for calculation. The distance of the GFRP $d_{\mathrm{GFRP}}$ is calculated as the strained distance of the walls before crack onset $d_{\text {walls }}$ minus the thickness of the dielectric air $d_{\text {air }}$, which is calculated from the counted number of cracks $n_{\text {cracks }}$ and the crack opening $d_{\text {crack. Including }}$ the assumptions, Eq. 4 is modified to Eq. 5. Capacitance change in per cent is calculated similar to the experimental capacitance change according to Eq. 3.

$$
C=\epsilon_{0} w d_{90} \frac{\epsilon_{\mathrm{r}, \mathrm{GFRP}} \epsilon_{\mathrm{r}, \mathrm{air}}}{\left(d_{\text {walls }}-n_{\text {cracks }} d_{\text {crack }}\right) \epsilon_{\mathrm{r}, \mathrm{air}}+n_{\text {cracks }} d_{\text {crack }} \epsilon_{\mathrm{r}, \mathrm{GFRP}}}
$$

For ease of calculation, only one plate capacitor is used for modelling. Therefore, the total counted cracks are divided by the total number of counted segments leading to decimal numbers of counted cracks. Micro-sections of the cracked specimens showed crack openings between $5 \mu \mathrm{m}$ and $15 \mu \mathrm{m}$ in the unloaded specimens. The crack opening varies from crack to crack and within a single crack depending on surrounding fibre arrangement and resin distribution. Therefore, crack opening is nonuniform over the thickness and width of the specimen. During the load application, the crack opening is bigger than in the unloaded specimens. The crack opening varies in the course of the tensile test. The first transverse crack develops when the stress in the $90^{\circ}$ layers equals its strength. After the first crack developed, the $0^{\circ}$ layers have to withstand additional stress. Load transfer between the longitudinal and transverse plies is governed by the shear stress at the interface. The crack opens further with higher load until additional transverse cracks develop when the stress transferred into the transverse ply exceeds the strength again. As a result of the crack formation, local stresses are reduced so that the crack opening of the surrounding cracks is decreased. Crack saturation is reached when the transferred stress in the $90^{\circ}$ layer does not exceed its strength anymore. The additional strain applied until fracture of the $0^{\circ}$ layers leads to crack opening of all transverse cracks. In the analytical modelling, a uniform crack opening which is not changing due to applied load is assumed for all cracks. Figure 11 shows the capacitance decrease resulting from the analytical model for two different crack openings compared to the measured capacitance decrease for a representative specimen with $18 \mathrm{~mm}$ conductor spacing. The dashed line shows the analytical results for a crack opening of $10 \mu \mathrm{m}$, which resembles the average of the crack openings measured in the micro-sections and therefore a lower estimate of the actual crack opening. Additionally, the dotted line shows the analytical capacitance decrease for

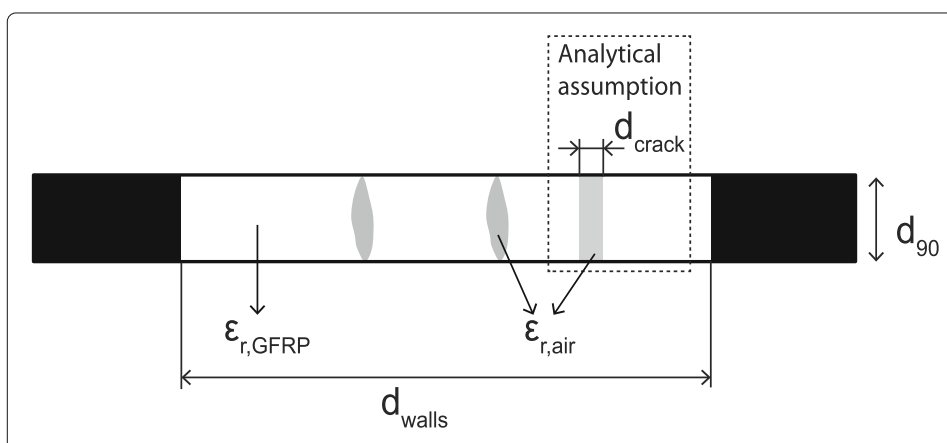

a)

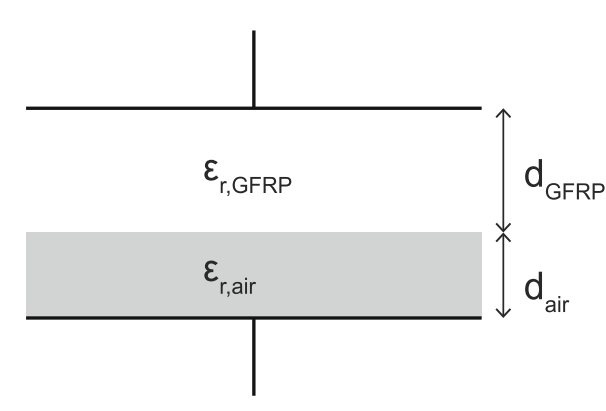

b)

Fig. 10 Parallel plate capacitor. Schematic of idealised plate capacitor formed between carbon fibre conductors in $90^{\circ}$ layer of the specimen including cracks and theoretic view as parallel plate capacitor for analytical modelling 


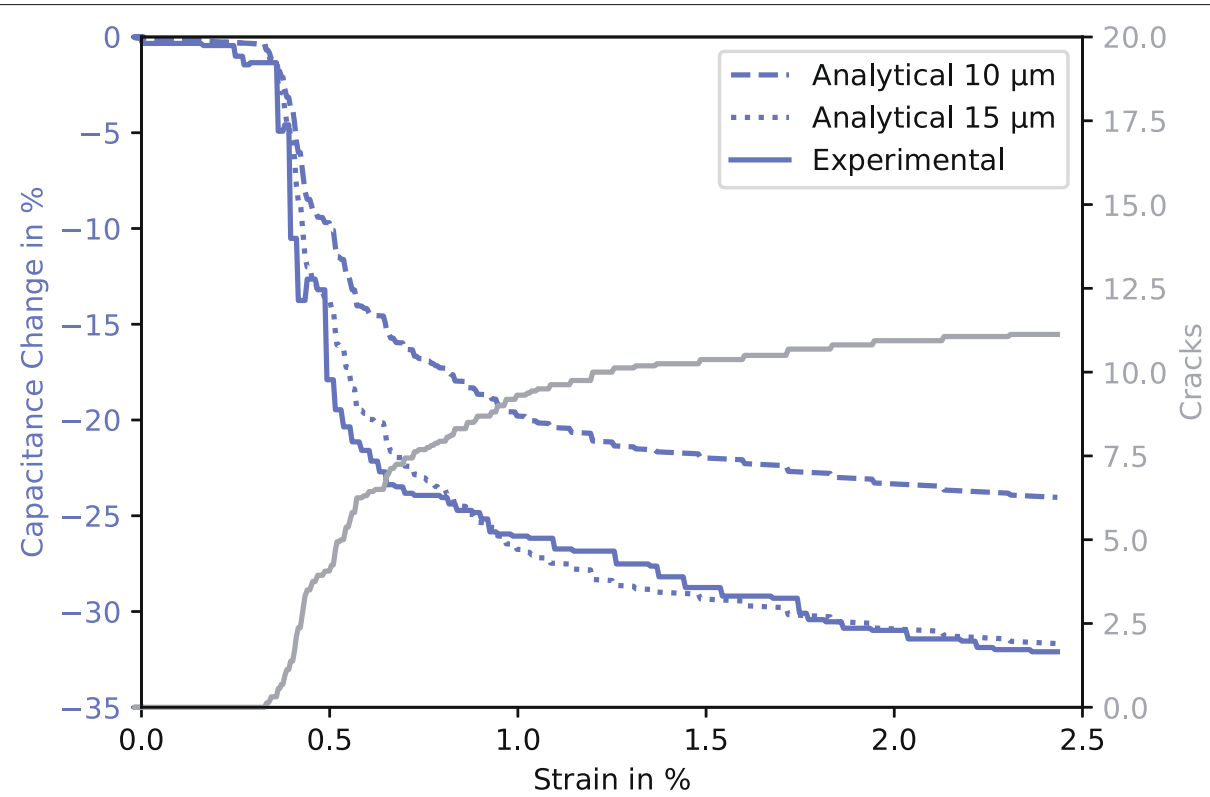

Fig. 11 Comparison of measured capacitance decrease with analytical modelling. Measured capacitance decrease of a representative CF conductor specimen compared with analytical modelling as ideal plate capacitor with dielectric property change due to air introduced by cracks for crack openings of $10 \mu \mathrm{m}$ (dashed line) and $15 \mu \mathrm{m}$ (dotted line) and distance change due to strain

$15 \mu \mathrm{m}$ crack opening. This value is chosen to represent the higher crack opening under load and show how the crack opening influences the analytical modelling. The actual crack opening is varying in the range of these two values. The modelling and the measured decrease are similar in shape. For lower strains and few cracks, both analytical models are in good agreement with the experimental capacitance decrease. For $10 \mu \mathrm{m}$ crack opening, the measurement shows a higher capacitance decrease than the analytical model from $0.45 \%$ strain onward. The modelling with a crack opening of $15 \mu \mathrm{m}$ qualitatively and quantitatively fits well to the experimental results. Especially for higher strains and when fewer cracks develop, the analytical modelling for the higher crack opening better reflects the experimental results. The part-wise slight overestimation and slight underestimation of the capacitance decrease for the higher crack opening fit to the assumption of a dynamic crack opening during the tensile tests. With assumptions regarding the crack opening, an analytical determination of the number of cracks and hence the damage state of the material is possible based on the measured capacitance decrease. In the manufactured specimens, some of the assumptions for an ideal plate capacitor made for simplicity of calculation (uniform electric field, uniform conductor distance, rectangular cracks with uniform opening, rectangular conductor area) are not entirely valid. However, the agreement between the theoretical and experimental values justifies the assumptions.

\section{Step-wise force-controlled tensile tests}

Force-controlled step-wise tensile tests on CF and solid copper conductor specimens have been performed to understand reversibility of the capacitance decrease and other influences as time-dependency and closing of cracks during unloading. Figure 12 includes representative results. The step-wise tests on specimens with CF conductors allow for similar conclusions as the tensile tests up to failure. The capacitance decrease is mainly crack driven and corresponds well to the counted cracks (compare vertical dashed lines) and stiffness decrease visible as knee-point. A smaller increase in crack count results in a smaller capacitance decrease. More sudden development of cracks leads to a faster capacitance decrease. Furthermore, the capacitance decrease due to cracks appears to be mostly irreversible. For higher strain, the capacitance shows a slight increase during unloading followed by a decrease with similar slope during re-loading until new cracks develop. This effect results from distance change due to strain as well as opening and closing of existing cracks and hence gets stronger with higher strain and crack number. A first small increase with unloading is visible after the third load step resembling $0.5 \%$ strain. This is in good agreement with the results of the analytical modelling (see Fig. 11). Below 0.45\% strain, the analytical capacitance decreases for both crack openings agree well with the experimental results. For low strains and a small number of cracks, the static crack opening determined from the micro-sections is suitable 


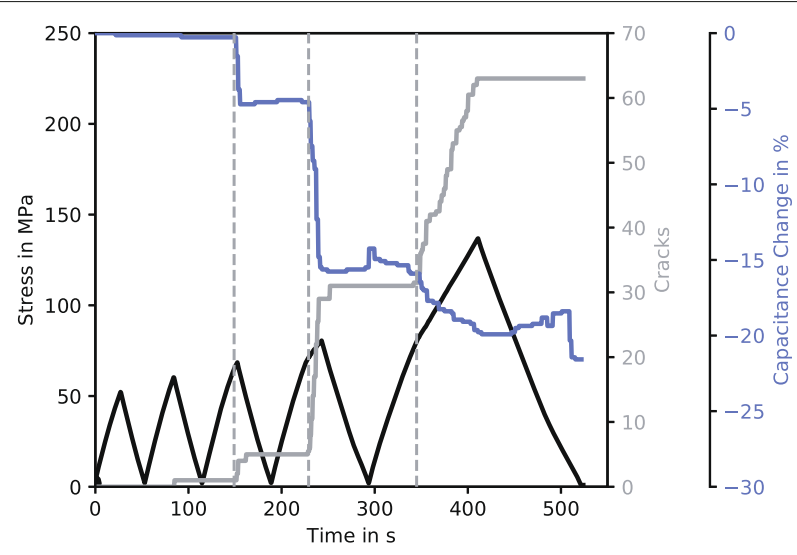

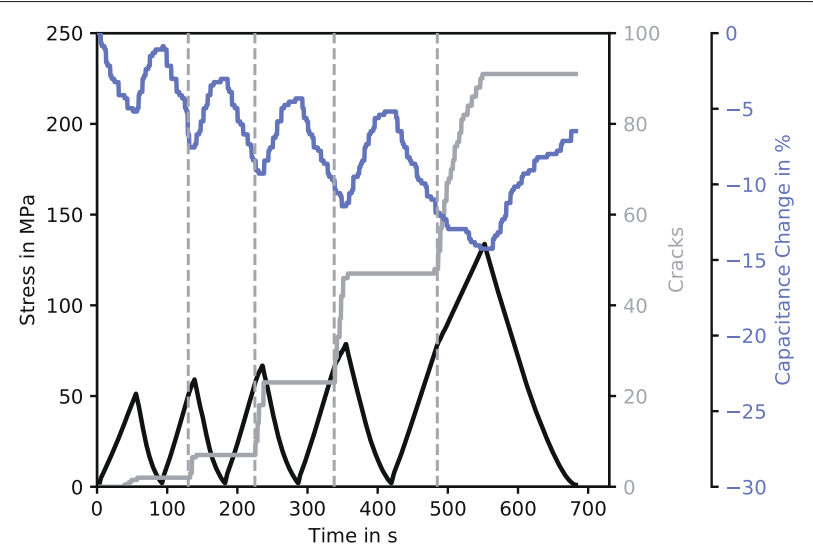

Fig. 12 Results of representative step-wise tensile tests. Stress in MPa, capacitance change in \% and counted cracks over time for step-wise tensile tests on representative specimens with a carbon fibre conductors $\mathbf{b}$ solid copper conductors

to describe the capacitance change since no significant effect of crack opening and closing is observed. Afterwards, the influence of the crack opening on the capacitance decrease increases. In general, step-wise tensile tests on CF conductor specimens show that the mostly irreversible capacitance change due to cracks enables a crack state evaluation with initial and current capacitance value without knowledge of complete capacitance curve. For solid copper conductors, the capacitance change shows a step-wise behaviour with maxima and minima opposing the force curve. The capacitance change during the single load steps seems to be mostly distance driven. However, the percentage change in capacitance is bigger than expected from a pure distance change of the conductors resulting from the applied strain. The crack evolution is not visible in the capacitance change with equal sensitivity as for the CF conductors. However, the influence of cracks on the capacitance is also evident with solid copper conductors. The non-reversible global reduction of the individual maximum values of the capacitance in the unloaded state between the individual force steps is crack driven. This effect was verified using a step-wise test with four $3400 \mathrm{~N}$ force steps followed by one $6800 \mathrm{~N}$ force step. During the first load step, some cracks developed, and the maximum of the capacitance after the first load step was smaller than the initial capacitance. Almost no new cracks formed in the remaining three load steps with equal force than the first step. Therefore, the individual maxima of the capacitance remained almost constant after the force steps. The higher force in the last step led to additional crack formation and the maximum capacitance value after this load step was smaller than after the previous load steps. Capacitance measurements on integrated solid copper conductors enable a conclusion about the damage state of the GFRP. However, in order to make a statement about the current state of damage without knowing the full capacitance curve, the specimen must be measured in the same load condition as during the initial capacitance measurement due to the strong influence of the strain. CF conductors beyond the sensitivity have the advantage, that due to the smaller distance influence a correlation of the capacitance measurements and the state of damage is possible even without knowledge of the applied load. The origin of the different behaviour of the capacitance decrease for the conductor types remains an open point for further investigations.

\section{Conclusion}

The presented new method of SHM in GFRP using integrated conductors enables in-situ damage state monitoring by means of capacitance change. Especially for embedded CF conductors, the capacitance decrease measured with increasing strain shows a high correlation with the number of cracks and the stiffness decrease (see Figs. 8 and 12). The knee-point in the stress-strain curve can precisely be detected by a drastic capacitance decrease, as shown in Fig. 8. The capacitance decreases more severely when many matrix cracks form, and less the more saturated the cracks are in the specimen. The capacitance decrease can be explained by the resulting permittivity change due to the lower permittivity of air within the formed cracks compared to intact GFRP. Analytical modelling of the experimental values is possible, including distance change of the capacitor plates and the permittivity changes caused by the formation of cracks with assumptions of an ideal plate capacitor. Step-wise tests confirm that the capacitance decrease due to cracks is mostly irreversible during unloading. Therefore, this method is capable of in-situ damage monitoring as well as damage state estimation with knowledge of capacitance decrease at 
specific points during the lifetime. A high surface area of the conductors as given in the case of CF conductors shows beneficial results for the sensitivity of crack detection. Solid copper conductors mainly show a distance driven linear effect with a lower irreversible change due to cracks. Therefore, CF conductors are most suitable and material-conforming conductor choice. They do not significantly alter the tensile strength or the Young's modulus of the cross-ply laminate and can easily be implemented in large composite structures by roving replacement in industrial manufacturing of non-crimp fabric. By embedding the conductors at different locations, layers and different material depths, the proposed method is a promising way to enable localised SHM within the structure. Areas of the structure that are difficult to access from the outside can be easily monitored using this SHM method.

\section{Abbreviations}

CF: Carbon fibre; CFRP: Carbon fibre reinforced polymer; DIC: Digital image correlation; GF: Glass fibre; GFRP: Glass fibre reinforced polymer; NDT: Non-destructive testing; SHM: Structural health monitoring

\section{Acknowledgements}

The authors would like to thank Mareile Kern for help with specimen preparation. The authors would like to thank Moritz Kruse for performing first trial experiments.

\section{Authors' contributions}

CB: Design and execution of the experiments, analysis of results, writing of the draft; AG: Help with development of the concept, editing and reviewing of the draft; BF: Project administration, funding acquisition, discussion of results, editing and reviewing of draft. All author(s) read and approved the final manuscript.

\section{Funding}

This research was funded by the Deutsche Forschungsgemeinschaft (DFG) 393868053. Open Access funding enabled and organized by Projekt DEAL.

\section{Availability of data and materials}

All data is stored on a secure server at the Institute of Polymer and Composites, Hamburg University of Technology. The datasets used and/or analysed during the current study are available from the corresponding author on reasonable request.

\section{Competing interests}

The authors declare that they have no competing interests.

\section{Author details}

${ }^{1}$ Hamburg University of Technology, Institute of Polymer and Composites, Denickestraße 15, 21073 Hamburg, Germany. ${ }^{2}$ Siemens Digital Industries Software, Via Werner von Siemens 1, 20128 Milano, Italy.

Received: 26 October 2020 Accepted: 16 December 2020

Published online: 12 January 2021

\section{References}

1. K. Schulte, C. Baron, Load and failure analyses of CFRP laminates by means of electrical resistivity measurements. Compos. Sci. Technol. 36(1), 63-76 (1989). https://doi.org/10.1016/0266-3538(89)90016-X

2. J. C. Abry, S. Bochard, A. Chateauminois, M. Salvia, G. Giraud, In situ detection of damage in CFRP laminates by electrical resistance measurements. Compos. Sci. Technol. 59(6), 925-935 (1999). https://doi. org/10.1016/S0266-3538(98)00132-8
3. M. Kupke, K. Schulte, R. Schüler, Non-destructive testing of FRP by d.c. and a.c. electrical methods. Compos. Sci. Technol. 61(6), 837-847 (2001). https://doi.org/10.1016/S0266-3538(00)00180-9

4. K. Takahashi, H. T. Hahn, Towards practical application of electrical resistance change measurement for damage monitoring using an addressable conducting network. Struct. Health Monit. 11(3), 367-377 (2012). https://doi.org/10.1177/1475921711424519

5. T. Augustin, D. Grunert, H. H. Langner, V. Haverkamp, B. Fiedler, Online monitoring of surface cracks and delaminations in carbon fiber/epoxy composites using silver nanoparticle based ink. Adv. Manuf. Polym. Compos. Sci. 3(3), 110-119 (2017). https://doi.org/10.1080/20550340. 2017.1362508

6. L. Böger, M. H. G. Wichmann, L. O. Meyer, K. Schulte, Load and health monitoring in glass fibre reinforced composites with an electrically conductive nanocomposite epoxy matrix. Compos. Sci. Technol. 68(7-8), 1886-1894 (2008). https://doi.org/10.1016/j.compscitech.2008.01.001

7. E. T. Thostenson, T. W. Chou, Real-time in situ sensing of damage evolution in advanced fiber composites using carbon nanotube networks. Nanotechnology. 19(21), 215713 (2008). https://doi.org/10. 1088/0957-4484/19/21/215713

8. I. Aguilar Ventura, J. Zhou, G. Lubineau, Drastic modification of the piezoresistive behavior of polymer nanocomposites by using conductive polymer coatings. Compos. Sci. Technol. 117, 342-350 (2015). https://doi. org/10.1016/j.compscitech.2015.07.007

9. N. D. Alexopoulos, C. Bartholome, P. Poulin, Z. Marioli-Riga, Structural health monitoring of glass fiber reinforced composites using embedded carbon nanotube (cnt) fibers. Compos. Sci. Technol. 70(2), 260-271 (2010). https://doi.org/10.1016/j.compscitech.2009.10.017

10. B. R. Loyola, K. J. Loh, V. La Saponara, in Sensors and Smart Structures Technologies for Civil, Mechanical, and Aerospace Systems 2011, SPIE Proceedings, ed. by M. Tomizuka. Static and dynamic strain monitoring of GFRP composites using carbon nanotube thin films (SPIE, 2011) p. 798108. https://doi.org/10.1117/12.881006

11. B. Pinto, S. Kern, J. J. Ku-Herrera, J. Yasui, V. La Saponara, K. J. Loh, A comparative study of a self strain-monitoring carbon nanotube film and carbon fibers under flexural loading by electrical resistance changes. J. Phys. Conf. Ser. 628, 012098 (2015). https://doi.org/10.1088/1742-6596/ 628/1/012098

12. B. R. Loyola, in Innovative Developments of Advanced Multifunctional Nanocomposites in Civil and Structural Engineering, ed. by K. J. Loh, S. Nagarajaiah. 14 - in situ sensing in glass fiber-reinforced polymer composites via embedded carbon nanotube thin films (Woodhead Publishing, Oxford, 2016), pp. 327-352. https://doi.org/10.1016/B978-178242-326-3.00014-2

13. K. Aly, A. Li, P. D. Bradford, In-situ monitoring of woven glass fiber reinforced composites under flexural loading through embedded aligned carbon nanotube sheets. J. Compos. Mater. 52(20), 2777-2788 (2018). https://doi.org/10.1177/0021998317754128

14. G. Yang, X. Feng, W. Wang, Q. OuYang, L. Liu, Z. Wu, Graphene and carbon nanotube-based high-sensitive film sensors for in-situ monitoring out-of-plane shear damage of epoxy composites. Compos. B Eng. 204, 108494 (2021). https://doi.org/10.1016/j.compositesb.2020.108494

15. J. Yan, A. Downey, A. Cancelli, S. Laflamme, A. Chen, J. Li, F. Ubertini, Concrete crack detection and monitoring using a capacitive dense sensor array. Sensors (Basel, Switzerland). 19(8), 1843 (2019). https://doi.org/10. 3390/s19081843

16. A. A. Nassr, W. W. El-Dakhakhni, Damage detection of FRP-strengthened concrete structures using capacitance measurements. J. Compos. Constr. 13(6), 486-497 (2009)

17. Y. Cheng, F. Gao, A. Hanif, Z. Lu, Z. Li, Development of a capacitive sensor for concrete structure health monitoring. Construct. Build. Mater. 149 659-668 (2017). https://doi.org/10.1016/j.conbuildmat.2017.05.150

18. Y. Cheng, A. Hanif, Z. Li, in Sensors and Smart Structures Technologies for Civil, Mechanical, and Aerospace Systems 2018, ed. by Hoon Sohn. Development of a flexible capacitive sensor for concrete structure health monitoring, vol. 10598 (SPIE, 2018), pp. 154-162. https://doi.org/10.1117/ 12.2306201

19. P. Hudec, C. MacInnis, M. Moukwa, The capacitance effect method of measuring moisture and salt content of concrete. Cem. Concr. Res. 16(4), 481-490 (1986). https://doi.org/10.1016/0008-8846(86)90085-2 
20. A. A. Nassr, W. H. Ahmed, W. W. El-Dakhakhni, Coplanar capacitance sensors for detecting water intrusion in composite structures. Meas. Sci. Technol. 19(7), 075702 (2008)

21. X. Yin, D. A. Hutchins, G. G. Diamond, P. Purnell, Non-destructive evaluation of concrete using a capacitive imaging technique: Preliminary modelling and experiments. Cem. Concr. Res. 40(12), 1734-1743 (2010). https://doi.org/10.1016/j.cemconres.2010.08.015

22. P. Chakraborty, N. B. Gundrati, C. Zhou, D. D. L. Chung, Effect of stress on the capacitance and electric permittivity of three-dimensionally printed polymer, with relevance to capacitance-based stress monitoring. Sensors Actuators A Phys. 263, 380-385 (2017). https://doi.org/10.1016/j.sna.2017. 07.008

23. P. Chakraborty, G. Zhao, C. Zhou, D. D. L. Chung, Unprecedented sensing of interlayer defects in three-dimensionally printed polymer by capacitance measurement. Smart Mater. Struct. 27(11), 115012 (2018) https://doi.org/10.1088/1361-665x/aae16e

24. J. C. Abry, Y. K. Choi, A. Chateauminois, B. Dalloz, G. Giraud, M. Salvia, Compos. Sci. Technol. 61(6), 855-864 (2001). https://doi.org/10.1016/ S0266-3538(00)00181-0

25. X. Yin, D. A. Hutchins, Non-destructive evaluation of composite materials using a capacitive imaging technique. Compos. B Eng. 43(3), 1282-1292 (2012). https://doi.org/10.1016/j.compositesb.2011.10.018

26. M. Morozov, W. Jackson, S. G. Pierce, Capacitive imaging of impact damage in composite material. Compos. B Eng. 113, 65-71 (2017). https://doi.org/10.1016/j.compositesb.2017.01.016

27. L. Lampani, F. Sarasini, J. Tirillò, P. Gaudenzi, Analysis of damage in composite laminates with embedded piezoelectric patches subjected to bending action. Compos. Struct. 202, 935-942 (2018). https://doi.org/10. 1016/j.compstruct.2018.04.073

28. C. Tuloup, W. Harizi, Z. Aboura, Y. Meyer, Integration of piezoelectric transducers (pzt and pvdf) within polymer-matrix composites for structural health monitoring applications: new success and challenges. Int J Smart Nano Mater., 1-27 (2020). https://doi.org/10.1080/19475411. 2020.1830196

29. I. M. d. Rosa, F. Sarasini, Use of PVDF as acoustic emission sensor for in situ monitoring of mechanical behaviour of glass/epoxy laminates. Polym. Test. 29(6), 749-758 (2010). https://doi.org/10.1016/j.polymertesting. 2010.04.006

30. S. Masmoudi, A. El Mahi, El Guerjouma, R., S. Turki, Mechanical behaviour and identification of damage by acoustic emission of smart composites Multidiscip. Model. Mater. Struct. 10(1), 2-17 (2014). https://doi.org/10. 1108/MMMS-11-2012-0023

31. S. Mall, J. M. Coleman, Monotonic and fatigue loading behavior of quasi-isotropic graphite/epoxy laminate embedded with piezoelectric sensor. Smart Mater. Struct. 7(6), 822-832 (1998). https://doi.org/10.1088/ 0964-1726/7/6/010

32. M. Yocum, H. Abramovich, A. Grunwald, S. Mall, Fully reversed electromechanical fatigue behavior of composite laminate with embedded piezoelectric actuator/sensor. Smart Mater. Struct. 12(4), 556-564 (2003). https://doi.org/10.1088/0964-1726/12/4/307

33. H. P. Konka, Embedded Piezoelectric Fiber Composite Sensors for Applications in Composite Structures (2011). LSU Doctoral Dissertations. 1983. https://digitalcommons.Isu.edu/gradschool_dissertations/1983

34. N. A. Chrysochoidis, E. Gutiérrez, Evaluation of the sensitivity and fatigue performance of embedded piezopolymer sensor systems in sandwich composite laminates. Smart Mater. Struct. 24(2), 025032 (2015). https:// doi.org/10.1088/0964-1726/24/2/025032

35. C. Tuloup, W. Harizi, Z. Aboura, Y. Meyer, K. Khellil, R. Lachat, On the use of in-situ piezoelectric sensors for the manufacturing and structural health monitoring of polymer-matrix composites: A literature review. Compos. Struct. 215, 127-149 (2019). https://doi.org/10.1016/j.compstruct.2019. 02.046

36. A. A. Eddib, D. D. L. Chung, First report of capacitance-based self-sensing and in-plane electric permittivity of carbon fiber polymer-matrix composite. Carbon. 140, 413-427 (2018). https://doi.org/10.1016/j. carbon.2018.08.070

37. R. Asmatulu, B. Venishetty, E. Asmatulu, in Proceedings of the ASME International Mechanical Engineering Congress and Exposition - 2009. Non-destructive testing of fiber reinforced composite materials using a capacitance bridge (ASME, New York, NY, 2010), pp. 171-177. https://doi. org/10.1115/IMECE2009-12335
38. S. A. Grammatikos, R. J. Ball, M. Evernden, R. G. Jones, Impedance spectroscopy as a tool for moisture uptake monitoring in construction composites during service. Compos. A: Appl. Sci. Manuf. 105, 108-117 (2018). https://doi.org/10.1016/j.compositesa.2017.11.006

39. DIN EN ISO 527-4:1997-07, Plastics - Determination of tensile properties Part 4: Test conditions for isotropic and anisotropic fibre-reinforced plastic composites (ISO 527- 4:1997) (1997). German verion EN ISO 527-4:1997

40. R. Zoughi, B. Zonnefeld, in Review of Progress in Quantitative Nondestructive Evaluation: Volume 10B, ed. by D. O. Thompson, D. E. Chimenti. Permittivity characteristics of kevlar, carbon composites, e-glass, and rubber (33\% carbon) at x-band (8-12 ghz) (Springer US, Boston, MA, 1991), pp. 1431-1436. https://doi.org/10.1007/978-1-4615-3742-7_38

41. V. I. Sokolov, S. I. Shalgunov, I. G. Gurtovnik, L. G. Mikheeva, I. D. Simonov-Emelyanov, Dielectric characteristics of glass fibre reinforced plastics and their components. Int. Polym. Sci. Technol. 32(7), 62-67 (2005). https://doi.org/10.1177/0307174X0503200715

42. Y. Wang, D. D. L. Chung, Effect of the fringing electric field on the apparent electric permittivity of cement-based materials. Compos. B Eng. 126, 192-201 (2017). https://doi.org/10.1016/j.compositesb.2017.05.080

\section{Publisher's Note}

Springer Nature remains neutral with regard to jurisdictional claims in published maps and institutional affiliations.

\section{Submit your manuscript to a SpringerOpen ${ }^{\circ}$ journal and benefit from:}

- Convenient online submission

- Rigorous peer review

- Open access: articles freely available online

- High visibility within the field

- Retaining the copyright to your article

Submit your next manuscript at $>$ springeropen.com 